\title{
Characteristics of Bilayer Molybdenum Films Deposited Using RF Sputtering for Back Contact of Thin Film Solar Cells
}

\author{
Sea-Fue Wang, ${ }^{1}$ Hsiao-Ching Yang, ${ }^{1}$ Chien-Fong Liu, ${ }^{1}$ and Huy-Yun Y. Bor ${ }^{2}$ \\ ${ }^{1}$ Department of Materials and Minerals Resources Engineering, National Taipei University of Technology, 1, Section 3, \\ Chung-Hsiao E. Road, Taipei 106, Taiwan \\ ${ }^{2}$ Materials \& Electro-Optics Research Division, Chung-Shan Institute of Science \& Technology, 481, Jiaian Sec., Zhongzheng Rd., \\ Longtan Township, Taoyuan County 325, Taiwan
}

Correspondence should be addressed to Sea-Fue Wang; seafuewang@yahoo.com

Received 25 February 2014; Accepted 24 May 2014; Published 18 June 2014

Academic Editor: Shuichi Miyazaki

Copyright (C) 2014 Sea-Fue Wang et al. This is an open access article distributed under the Creative Commons Attribution License, which permits unrestricted use, distribution, and reproduction in any medium, provided the original work is properly cited.

\begin{abstract}
Mo films prepared under a single deposition condition seldom simultaneously obtain a low resistivity and a good adhesion necessary for use in solar cells. In order to surmount the obstacle, bilayer Mo films using DC sputtering at a higher working pressure and a lower working pressure have been attempted as reported in the literature. In this study, RF sputtering with different powers in conjunction with different working pressures was explored to prepare bilayer Mo film. The first bottom layer was grown at a RF sputtering power of $30 \mathrm{~W}$ and a working pressure of $12 \mathrm{mTorr}$, and the second top layer was deposited at $100 \mathrm{~W}$ and $4.5 \mathrm{mTorr}$. The films revealed a columnar growth with a preferred orientation along the (110) plane. The bilayer Mo films reported an electrical resistivity of $6.35 \times 10^{-5} \Omega-\mathrm{cm}$ and passed the Scotch tape test for adhesion to the soda-lime glass substrate, thereby qualifying the bilayer Mo films for use as back metal contacts for CIGS substrates.
\end{abstract}

\section{Introduction}

The back contact (BC) for $\mathrm{CuLnSe}_{2}$ (CIS) and $\mathrm{Cu}\left(\operatorname{In}_{1-x} \mathrm{Ga}_{x}\right) \mathrm{Se}_{2}$ (CIGS) solar cells needs to meet the following requirements [1]: low resistivity, low sheet resistance, good adhesion to the soda-lime glass (SLG) substrate, a thermal expansion coefficient close to that of CIGS, relatively stable processing temperature, and low roughness. Moreover, good chemical inertness that impedes any reaction during CIGS deposition is required so as to help the Na on the SLG substrate to diffuse into CIGS [2] and to acquire a high light reflectivity within the visible spectrum range. In addition to good ohmic contact with the CIGS thin film [3], BC requires a high reflectivity to reflect the light back to the absorption layer for increasing photon absorption and transforming light energy into power [4]. A trend deserving special attention is that, for lowering manufacturing cost, the development of CIGS solar cell has moved toward reducing the thickness of the absorption layer, a move that decreases the degree of light absorption. The reflectivity of $\mathrm{BC}$ thus becomes a particularly important parameter for enhancing the efficiency of solar cell.

Among the $\mathrm{BC}$ metals (W, Mo, Cr, Ta, Nb, V, Ti, Mn, $\mathrm{Au}, \mathrm{Ni}, \mathrm{Al}, \mathrm{Ag}, \mathrm{Cu}$, and $\mathrm{Pt})$ in the $\mathrm{Cu}(\mathrm{In}, \mathrm{Ga}) \mathrm{Se}_{2}$ thin film solar cell reported in the literature [5-7], Ti, V, Cr, and $\mathrm{Mn}$ films were observed to react with Se during CIGS deposition and further influence CIGS growth, while Au and Pt would diffuse into the CIGS layer during deposition. $\mathrm{Au}, \mathrm{Ti}, \mathrm{Mo}$, and $\mathrm{Ni}$ films appeared to reveal low contact resistances to the CIGS absorption layer after high-temperature annealing, but only $\mathrm{Ni}$ and Mo films exhibited good ohmic contact. With a wave length less than $700 \mathrm{~nm}$ in the visible spectrum, Mo film displayed a better reflectivity than $\mathrm{W}, \mathrm{Ta}$, and $\mathrm{Nb}$ films under the same CIGS thickness. The Mo film was further found to demonstrate good electrical performance (low resistivity), relatively stable processing temperature, and good ohmic contact with the CIGS thin film. Bilayer Mo films were prepared by D.C. sputtering, in which the bottom layer was deposited at a higher Ar pressure for better adhesion and 
the top layer was formed at a lower pressure to guarantee a lower resistivity $[5,8]$.

The vigorous development of CIGS solar cell has triggered a corresponding rise in the importance of studies for understanding the processing-microstructure-property relations of Mo thin film, which form a crucial factor influencing the absorption layer. Though Mo has been used extensively by a considerable number of research groups and members of the CIGS industry in the market, clear deposition properties of such a layer, particularly one deposited by radiofrequency (R.F.) sputtering, have not been reported in the literature [5, $6,9]$. The purpose of this study is accordingly to examine the potential impacts of processing parameters during deposition via R.F. magnetron sputtering on the performance of Mo films, through the characterizations of scanning electron microscope (SEM), electrical conductivity measurement, and reflectivity measurement. Bilayer Mo films deposited, respectively, at a lower power and a higher power were also explored to check their potential of achieving a better adhesion and a lower resistivity.

\section{Experimental Methods}

In this study, Mo films were deposited on glass substrates (EAGLE $^{2000}$, Corning Incorporated) by the R.F. magnetron sputtering of a high-purity molybdenum target (99.99\%; Kao Duen Technology Corp., Taiwan) in a chamber with a base pressure of $<7 \times 10^{-6}$ Torr. Prior to the deposition, glass EAGLE $^{2000}$ with a dimension of $30 \mathrm{~mm} \times 30 \mathrm{~mm} \times 0.7 \mathrm{~mm}$ was cleaned for 15 minutes in an ultrasonic cleaner with a solution comprising acetone, methyl-alcohol, and DI water and dried by a nitrogen blower. The molybdenum target was characterized and reported a BCC structure with a density of $10.02 \mathrm{~g} / \mathrm{cm}^{3}$ (corresponds to $99 \%$ of theoretical density) and an average grain size of $108 \mu \mathrm{m}$. The films were sputtered onto the glass substrates without being heated, resulting in a deposition temperature of $\sim 80^{\circ} \mathrm{C}$ (measured using a thermocouple under the glass substrate). Pure argon was used to deposit the Mo films. Before deposition, the target was sputtercleaned for at least 10 hours. Sputtering powers 50$150 \mathrm{~W}$, working pressures of 4.5 to $12 \mathrm{mTorr}$, and flow rates of 10 to $30 \mathrm{sccm}$ were used to deposit the Mo films.

Crystallographic evolution of the films was examined and crystallized phases identified by a thin film XRD (Rigaku D/max-B) with monochromatic $\mathrm{Cu} \mathrm{K} \alpha$ radiation. Microstructural analyses were conducted by a FESEM (field emission scanning electron microscope, HITACHI S-4700), that was also used to measure the film thickness to help determine the deposition rates. The optical properties were investigated by UV-vis spectrophotometers (LAMBDA 900). The electrical resistivities of the Mo films were measured using a 4-point probe method with KEITHLEY 2400. The adhesion to the substrate after deposition was tested by Scotch tape test $[6,10]$ method. The carrier mobility of the Mo films was investigated by a Hall-effect measurement system (ECOPIA HMS-3000 ver. 3.5). The samples were scratched to a rectangle shape and adhesive tape stripes of the same

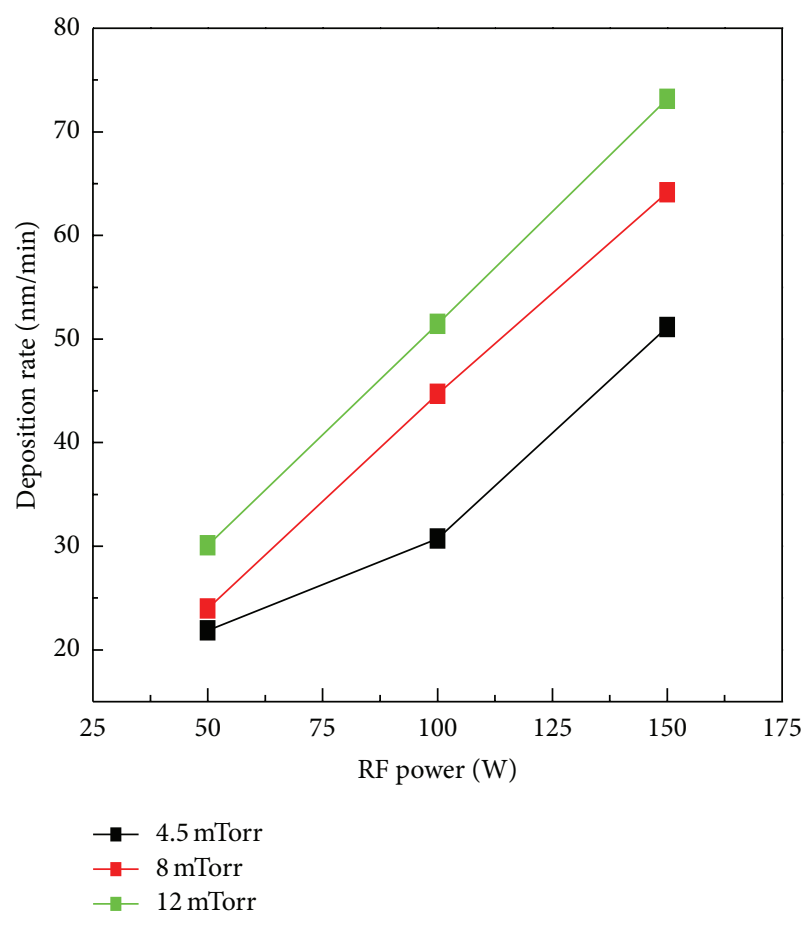

FIGURE 1: Deposition rates of Mo films prepared at different RF powers and working pressures.

length were glued on the scratched films and stripped with approximately equal amounts of force.

\section{Results and Discussion}

Figure 1 shows the influence of the sputtering power on the deposition rate of the Mo films at different working pressures. As indicated by the results, the deposition rate of Mo films rose as the RF power and the working pressure of Ar increased. As the RF power escalated from 50 to $150 \mathrm{~W}$, the deposition rate accelerated from 21.8 to $30.1 \mathrm{~nm} / \mathrm{min}$ at the working pressure of 4.5 mTorr; similar increases were observed at the working pressures of 8 mTorr (from 30.7 to $51.5 \mathrm{~nm} / \mathrm{min}$ ) and $12 \mathrm{mTorr}$ (from 51.2 to $73.2 \mathrm{~nm} / \mathrm{min}$ ). The trend of the deposition rate as a function of RF sputtering power is apparently consistent with the typical observation reported in the literature, which is due to the kinetic energy of the $\mathrm{Ar}^{+}$bombardment amplified by the sputtering power. With the Ar working pressure in the range from 4.5 to 12 mTorr, the $\mathrm{Ar}^{+}$concentration increased with the working pressure, while the deposition rate would level off if the working pressure continued to rise, caused by the increase in the frequency of the collision of the gas species in the plasma that reduced the mean free path [1].

According to Figure 2 that presents the XRD patterns of the Mo films prepared at RF sputtering powers and working pressures of $100 \mathrm{~W}$ and $12 \mathrm{mTorr}, 100 \mathrm{~W}$ and $4.5 \mathrm{mTorr}$, and $30 \mathrm{~W}$ and 12 mTorr, all films showed a typical body-centered cubic (BCC) Im $3 \mathrm{~m}$ Mo structure with three main peaks corresponding to the orientation along (110), (211), and (220) directions. The intensities of the XRD peaks indicated that 
TABLE 1: Physical characteristics of Mo films prepared under different deposition conditions.

\begin{tabular}{|c|c|c|c|c|c|c|c|}
\hline $\mathrm{RF}(\mathrm{W})$ & $\operatorname{Ar}(\mathrm{sccm})$ & W.P. (mTorr) & Sputtering time $(\mathrm{min})$ & Resistivity $(\Omega \cdot \mathrm{cm})$ & Mobility $\left(\mathrm{cm}^{2} / \mathrm{Vs}\right)$ & Adhesion (pass/fail) & Reflectivity (\%) \\
\hline 30 & 30 & 12 & 20 & $5.41 \times 10^{-4}$ & - & Pass & - \\
\hline 30 & 30 & 4.5 & 20 & $2.13 \times 10^{-4}$ & 0.36 & Fail & - \\
\hline 50 & 30 & 4.5 & 20 & $9.29 \times 10^{-5}$ & 1.10 & Fail & 51.09 \\
\hline 100 & 30 & 4.5 & 20 & $6.10 \times 10^{-5}$ & 4.55 & Fail & - \\
\hline 150 & 30 & 4.5 & 20 & $7.35 \times 10^{-5}$ & 9.89 & Fail & - \\
\hline 100 & 30 & 4.5 & 20 & $6.10 \times 10^{-5}$ & 4.09 & Fail & 52.74 \\
\hline 100 & 30 & 8 & 20 & $2.34 \times 10^{-4}$ & 1.80 & Pass & - \\
\hline 100 & 30 & 12 & 20 & $3.66 \times 10^{-4}$ & 0.86 & Pass & - \\
\hline $30 / 100$ & 30 & $12 / 4.5$ & $10 / 20$ & $6.35 \times 10^{-5}$ & 4.53 & Pass & 52.63 \\
\hline
\end{tabular}

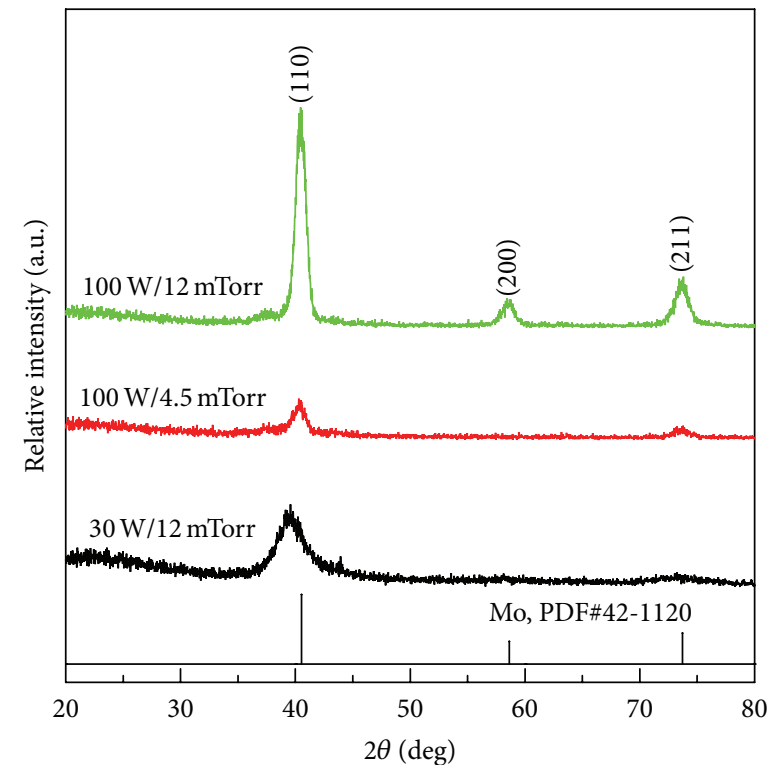

FIGURE 2: XRD patterns of Mo films prepared at different RF sputtering powers and working pressures: (a) $100 \mathrm{~W} / 12$ mTorr, (b) $100 \mathrm{~W} / 4.5$ mTorr, and (c) $30 \mathrm{~W} / 12$ mTorr.

the films grew with a preferred orientation along the (110) plane, a typical feature of the Mo films deposited by sputtering processes at room temperature [11]. The (110) planes on BCC lattice materials possess the highest planar density and the minimum surface free energy. It was noted that, among the three deposition conditions, the film deposited at a sputtering power of $100 \mathrm{~W}$ and a working pressure of $12 \mathrm{mTorr}$ accomplished the highest crystallization assessed from the highest XRD peak intensity and the decrease in the (110) FWHM. It was thus obvious that a higher sputtering power helped achieve enhanced crystallization, while the working pressure seemed to exert less influence on film crystallinity.

Figure 3 presents the electrical resistivities of the Mo films prepared at different RF sputtering powers and Ar working pressures. Parts of the results are also listed in Table 1. It should be noted that, in this study, the electrical resistivity of the Mo film showed no correlation with the film thickness in the thickness range, similar to those observed in the literature $[5,8]$. The effect of the sputtering power on the electrical

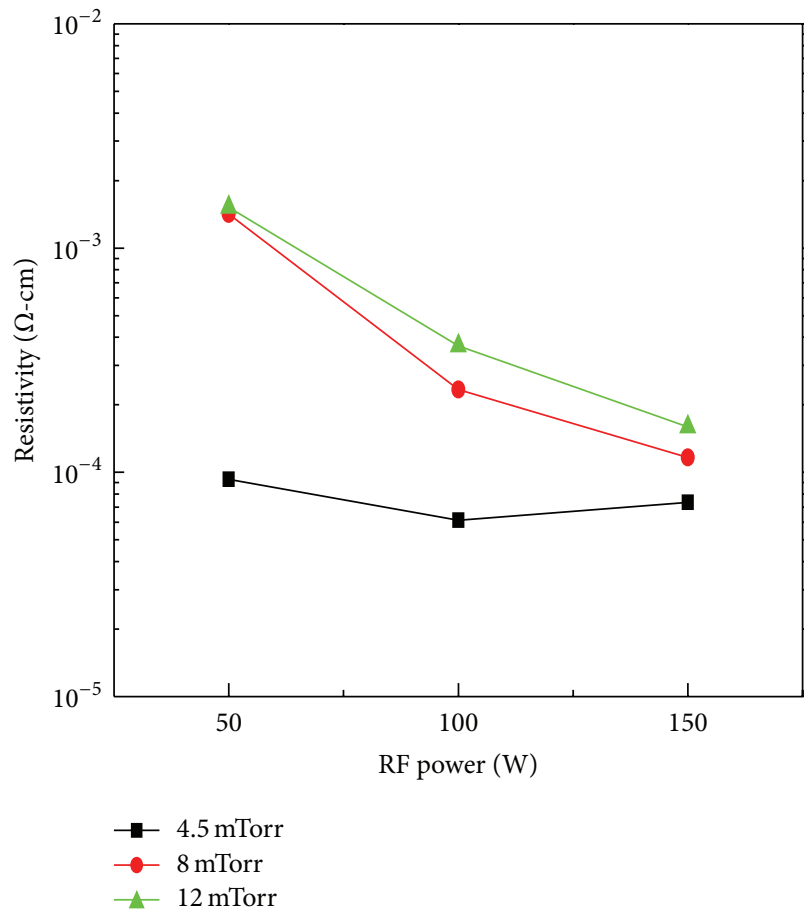

FIGURE 3: Resistivities of Mo films prepared at different RF sputtering powers and working pressures.

resistivity of the Mo film depended on the working pressure used. The electrical resistivities of the films grown at 8 and 12 mTorr decreased dramatically with escalating sputtering power. As the sputtering power rose from 50 to $100 \mathrm{~W}$, the electrical resistivities, showing approximately an order in reduction, varied from $1.42 \times 10^{-3}$ to $1.16 \times 10^{-4} \Omega-\mathrm{cm}$ and from $1.52 \times 10^{-3}$ to $1.59 \times 10^{-4} \Omega-\mathrm{cm}$, respectively, at the working pressures of 8 and 12 mTorr. On the other hand, the effect of sputtering power on the electrical resistivity of the Mo films deposited at a working pressure of $4.5 \mathrm{mTorr}$ appeared to be insignificant. Carefully inspecting the effect of the Ar working pressure on the electrical resistivity, the study found that the Mo films revealed an increased electrical resistivity as the Ar working pressure escalated from 4.5 to $8 \mathrm{mTorr}$, and the change in the electrical resistivity slackened with the increase in the sputtering power. For instance, 


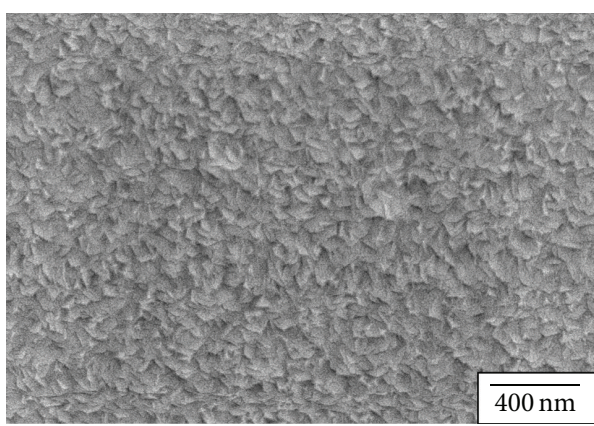

(a)

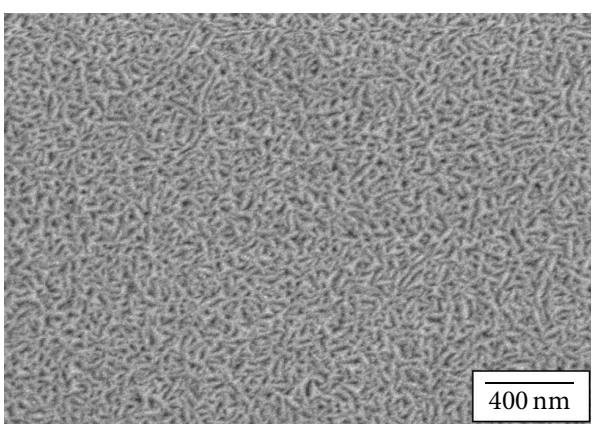

(b)

FIGURE 4: Top surface SEM images of Mo films prepared at a sputtering power of $100 \mathrm{~W}$ and working pressures of (a) $4.5 \mathrm{mTorr}$ and (b) 12 mTorr.

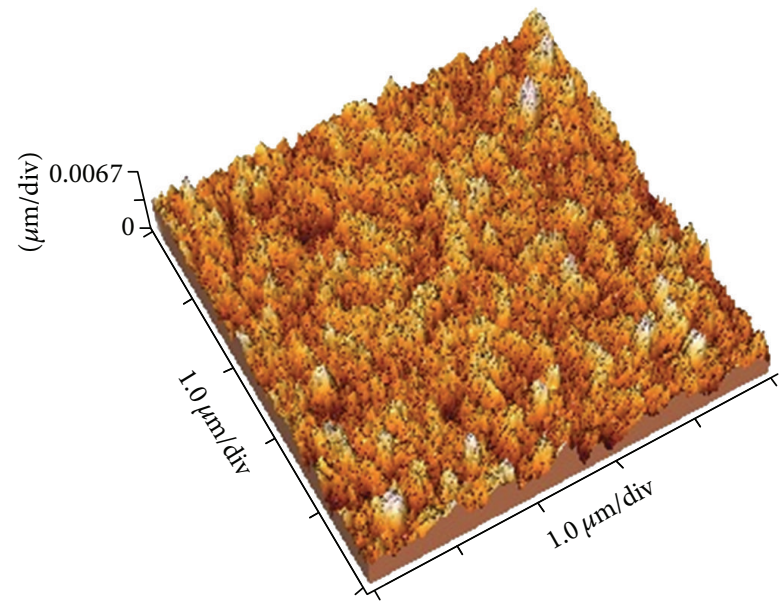

(a)

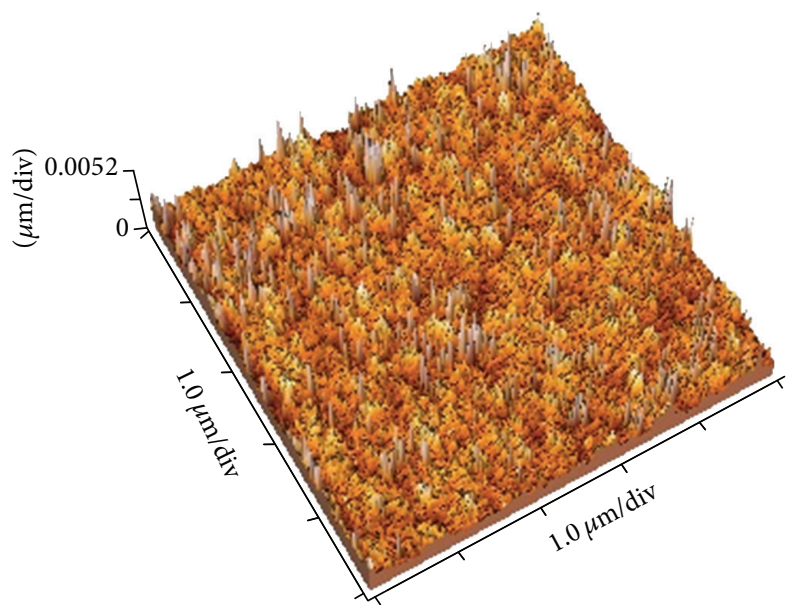

(b)

Figure 5: Top surface AFM images of Mo films prepared at a sputtering power of $100 \mathrm{~W}$ and working pressures of (a) $4.5 \mathrm{mTorr}$ and (b) 12 mTorr.

increasing the Ar working pressure from 4.5 to 8 mTorr augmented the electrical resistivities from $9.29 \times 10^{-5}$ to $1.42 \times 10^{-3} \Omega$-cm and from $7.36 \times 10^{-5}$ to $1.59 \times 10^{-4} \Omega$-cm for the films deposited at 50 and $150 \mathrm{~W}$, respectively. However, the difference in electrical resistivity was trivial between the films grown at working pressures of 8 and 12 mTorr. A similar observation in the trend of electrical resistivity versus working pressure was reported by Khatri and Marsillac [6], while Jubault et al. showed that the electrical resistivities of the Mo films prepared in the range from 2 to 20 mTorr revealed no significant change [1].

The change in the electrical resistivity of the films could be mainly attributed to the difference in microstructural evolution. Typical examples are shown in Figure 4 for the Mo films prepared at a sputtering power of $100 \mathrm{~W}$ and the different working pressures of $4.5 \mathrm{mTorr}$ and $12 \mathrm{mTorr}$. The film deposited at $4.5 \mathrm{mTorr}$ displayed a larger and more densely packed grain microstructure with closed boundaries and formation of less voids (Figure 4(a)), due to the fact that the Mo particles have a longer free pathway and a higher kinetic energy during deposition. This compactness provided good electrical continuity and the small number of grain boundaries increased the carrier mobility, which resulted in a lower electrical resistivity (Table 1). For the film deposited at 12 mTorr, the presence of intergranular voids and porous structures in the Mo film was caused by the lower kinetic energies of Mo particles during deposition, which led to a higher electrical resistivity. Similar results were also displayed in the AFM surface topography shown in Figure 5, which revealed the grain size of the Mo film on the glass substrates. Compared to its counterpart at $4.5 \mathrm{mTorr}$, the Mo film deposited at a working pressure of $12 \mathrm{mTorr}$, appeared to be rougher, and reported a smaller grain size. The average RMS roughness escalated from $9.5 \mathrm{~nm}$ to $15.6 \mathrm{~nm}$ as the working pressure increased from 4.5 to 12 mTorr. The carrier mobility of the Mo films, as obtained from Halleffect measurement, was listed in Table 1 . The carrier mobility dropped with the working pressure and increased with RF sputtering powers during deposition, which confirmed the electrical resistivity of the Mo films observed.

Adhesion of Mo films to the soda-lime glass substrates, a major determinant of solar cell performance, was found to be 


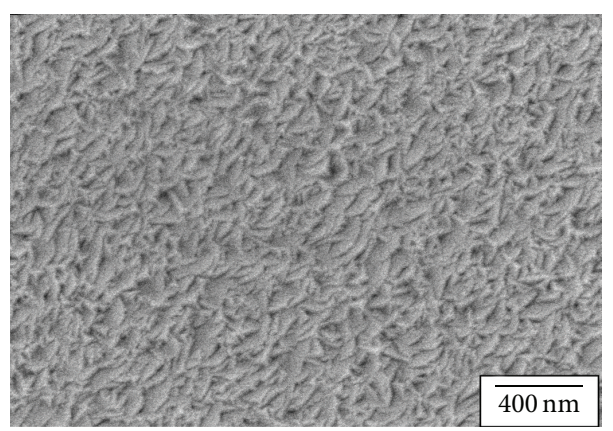

(a)

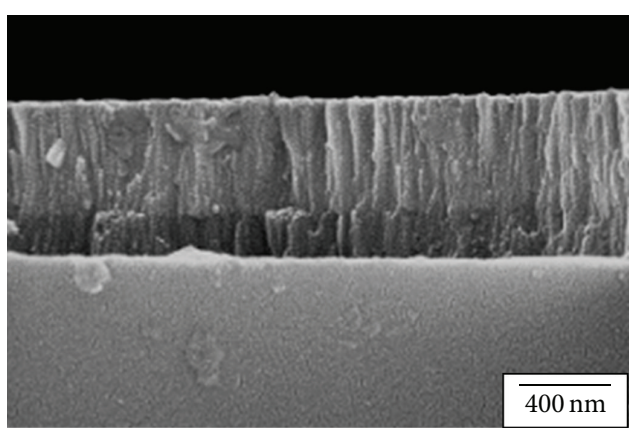

(b)

FIGURE 6: SEM images of (a) the top surface and (b) the fracture surface of the bilayer Mo films prepared at $30 \mathrm{~W} / 12 \mathrm{mTorr}$ for $10 \mathrm{~min}$ and subsequently at $100 \mathrm{~W} / 4.5 \mathrm{mTorr}$ for $20 \mathrm{~min}$.

correlated with the working pressure and the RF sputtering power. After cleaning in isopropyl alcohol, the adhesion was qualitatively evaluated by "Scotch tape test." According to the pass-fail results presented in Table 1, the Mo films failed the adhesion test when they were deposited at a working pressure of 4.5 mTorr. Since the microstructure was tightly packed (Figure 4), the Mo film tended to be under compressive stress, thus poor adhesion to the substrate [5]. For the films grown at working pressures of 8 and 12 mTorr, good adhesion between the Mo films and soda-lime glass substrates was obtained. It should be noted that adhesion of the Mo film to the substrates appeared to be weaker as the sputtering power increased. The tendency is due to the fact that the less frequent formation of microvoids at high sputtering power leads to low resistivity and poor adhesion $[5,6]$.

Both low resistivity and good adhesion are desirable features for a back contact metallized layer used in solar cells. However, based on the results listed in Table 1, the Mo films prepared under a single deposition condition failed to acquire simultaneously low resistivity and good adhesion. To overcome the weakness, the performance of a bilayer Mo film at sequentially different sputtering powers and different working pressures during the deposition process was explored. The first bottom layer was grown at a sputtering power of $30 \mathrm{~W}$ and a working pressure of $12 \mathrm{~m}$ Torr to ensure good adhesion. Afterward, the second top layer was deposited at a sputtering power of $100 \mathrm{~W}$ and a working pressure of 4.5 mTorr to obtain a low-resistivity film. Figure 6 shows the SEM images of the top surface and the fracture surface of the bilayer Mo films prepared at $30 \mathrm{~W} / 12 \mathrm{mTorr}$ for $10 \mathrm{~min}$ and subsequently at $100 \mathrm{~W} / 4.5 \mathrm{mTorr}$ for $20 \mathrm{~min}$. The thicknesses of the first and the second Mo layers were, respectively, 215 and $520 \mathrm{~nm}$. The film shows a columnar growth with a visible junction between the top and the bottom Mo layers. The electrical resistivity of the bilayer Mo film was measured to be $6.35 \times 10^{-5} \Omega-\mathrm{cm}$, close to that of the single-layer Mo film $\left(6.10 \times 10^{-5} \Omega-\mathrm{cm}\right)$ prepared at a sputtering power of $100 \mathrm{~W}$ and a working pressure of 4.5 mTorr (the same deposition condition for the top layer). The bilayer MO film passed the Scotch tape test for adhesion to the soda-lime glass substrate. The reflectivity of the bilayer Mo film was found to be $53 \%$ in the visible spectrum.
It is reported in the literature that the single-layer Mo films deposited using RF sputtering outperform those grown by DC sputtering in terms of conductivity, density, and adhesion to the soda-lime glass substrate [1]. Different from several previous studies preparing bilayer Mo films using DC sputtering at a higher working pressure and a lower working pressure $[5,9,12]$, this study utilized different RF sputtering powers in conjunction with different working pressures to prepare bilayer Mo films. Results show that the bilayer Mo films were suitable for use as back metal contacts of CIGS solar cells as both good adhesion to the soda-lime glass substrate and low resistivity were achieved.

\section{Conclusions}

In this study, bilayer Mo films were successfully prepared using RF sputtering. The bottom layer was grown at a sputtering power of $30 \mathrm{~W}$ and a working pressure of $12 \mathrm{mTorr}$ to pass Scotch tape test for adhesion to the soda-lime glass substrate. The top layer was deposited at a sputtering power of $100 \mathrm{~W}$ and a working pressure of 4.5 mTorr to obtain a low electrical resistivity of $6.35 \times 10^{-5} \Omega-\mathrm{cm}$. The films revealed a columnar growth with a preferred orientation along the (110) plane. The reflectivity of the bilayer Mo film was found to be $53 \%$ in the visible spectrum. These results verify that the bilayer Mo films prepared by the study are suitable for use as back metal contacts of CIGS solar cells.

\section{Conflict of Interests}

The authors declare that there is no conflict of interests regarding the publication of this paper.

\section{References}

[1] M. Jubault, L. Ribeaucourt, E. Chassaing, G. Renou, D. Lincot, and F. Donsanti, "Optimization of molybdenum thin films for electrodeposited CIGS solar cells," Solar Energy Materials and Solar Cells, vol. 95, no. 1, pp. S26-S31, 2011.

[2] J.-H. Yoon, S. Cho, W. M. Kim et al., "Optical analysis of the microstructure of a Mo back contact for $\mathrm{Cu}(\mathrm{In}, \mathrm{Ga}) \mathrm{Se}_{2}$ solar cells and its effects on Mo film properties and Na diffusivity," Solar 
Energy Materials and Solar Cells, vol. 95, no. 11, pp. 2959-2964, 2011.

[3] T. Wada, N. Kohara, S. Nishiwaki, and T. Negami, "Characterization of the $\mathrm{Cu}(\mathrm{In}, \mathrm{Ga}) \mathrm{Se}_{2} / \mathrm{Mo}$ interface in CIGS solar cells," Thin Solid Films, vol. 387, no. 1-2, pp. 118-122, 2001.

[4] K. Orgassa, H. W. Schock, and J. H. Werner, "Alternative back contact materials for thin film $\mathrm{Cu}(\mathrm{In}, \mathrm{Ga}) \mathrm{Se}_{2}$ solar cells," Thin Solid Films, vol. 431-432, pp. 387-391, 2003.

[5] P. M. P. Salomè, J. Malaquias, P. A. Fernandes, and A. F. da Cunha, "Mo bilayer for thin film photovoltaics revisited," Journal of Physics D: Applied Physics, vol. 43, no. 34, Article ID 345501, 2010.

[6] H. Khatri and S. Marsillac, "The effect of deposition parameters on radiofrequency sputtered molybdenum thin films," Journal of Physics Condensed Matter, vol. 20, no. 5, Article ID 055206, 2008.

[7] C. Dicov, M. Marinov, H. Maciel, K. Grigorov, I. Nedkov, and G. Beshkov, "Properties of $\mathrm{Cr}$ and Mo thin films deposited by RF sputtering," Journal of Optoelectronics and Advanced Materials, vol. 7, no. 1, pp. 385-387, 2005.

[8] Z.-H. Li, E.-S. Cho, and S. J. Kwon, "Molybdenum thin film deposited by in-line DC magnetron sputtering as a back contact for $\mathrm{Cu}(\mathrm{In}, \mathrm{Ga}) \mathrm{Se}_{2}$ solar cells," Applied Surface Science, vol. 257, no. 22, pp. 9682-9688, 2011.

[9] G. Gordillo, F. Mesa, and C. Calderón, "Electrical and morphological properties of low resistivity Mo thin films prepared by magnetron sputtering," Brazilian Journal of Physics, vol. 36, no. 3, pp. 982-985, 2006.

[10] K. L. Mittal, "Adhesion measurement of thin films," Electrocomponent Science and Technology, vol. 3, no. 1, pp. 21-42, 1976.

[11] L. Assmann, J. C. Bernède, A. Drici, C. Amory, E. Halgand, and M. Morsli, "Study of the Mo thin films and Mo/CIGS interface properties," Applied Surface Science, vol. 246, no. 1-3, pp. 159166, 2005.

[12] J. H. Scofield, A. Duda, D. Albin, B. L. Ballard, and P. K. Predecki, "Sputtered molybdenum bilayer back contact for copper indium diselenide-based polycrystalline thin-film solar cells," Thin Solid Films, vol. 260, no. 1, pp. 26-31, 1995. 

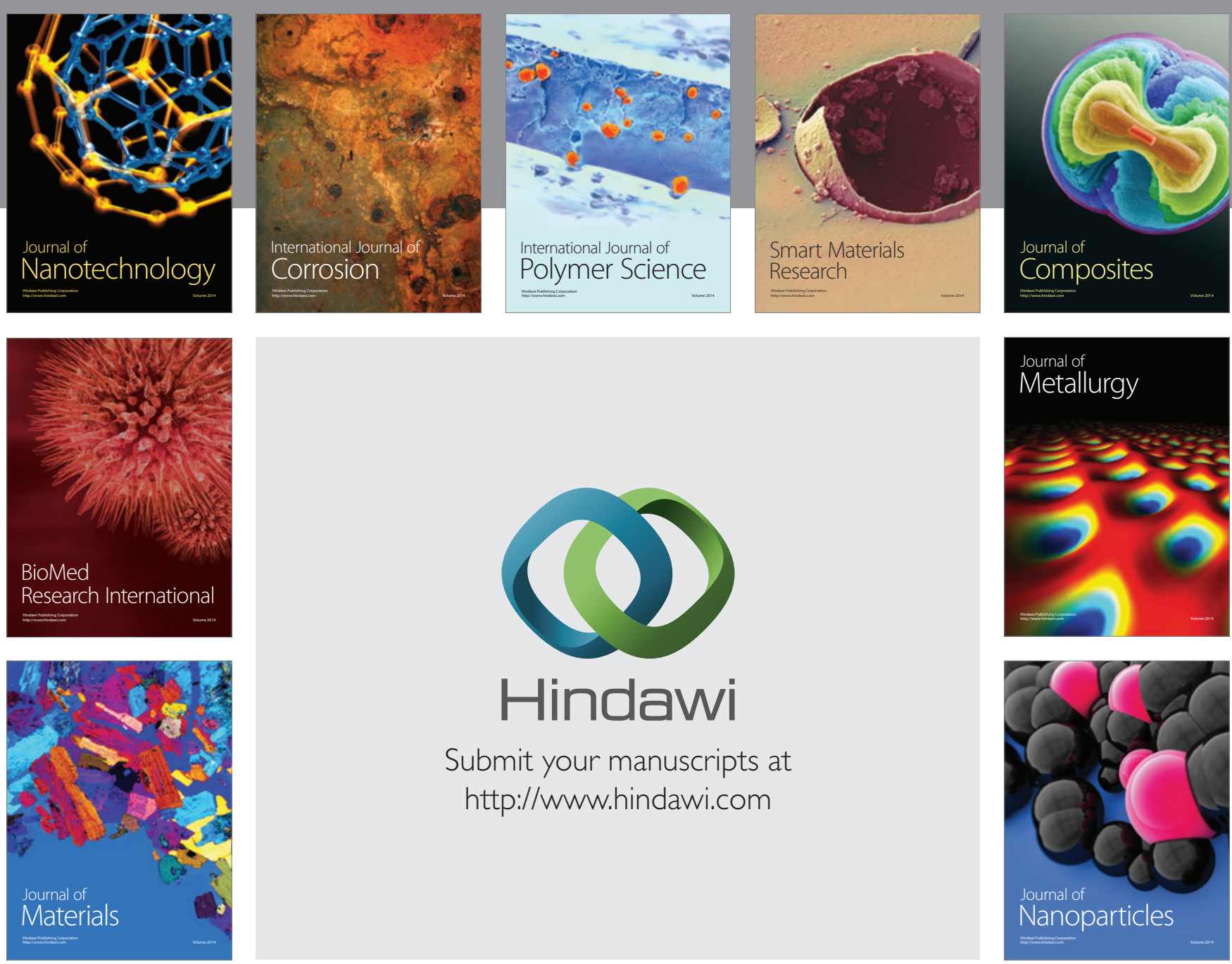

Submit your manuscripts at http://www.hindawi.com
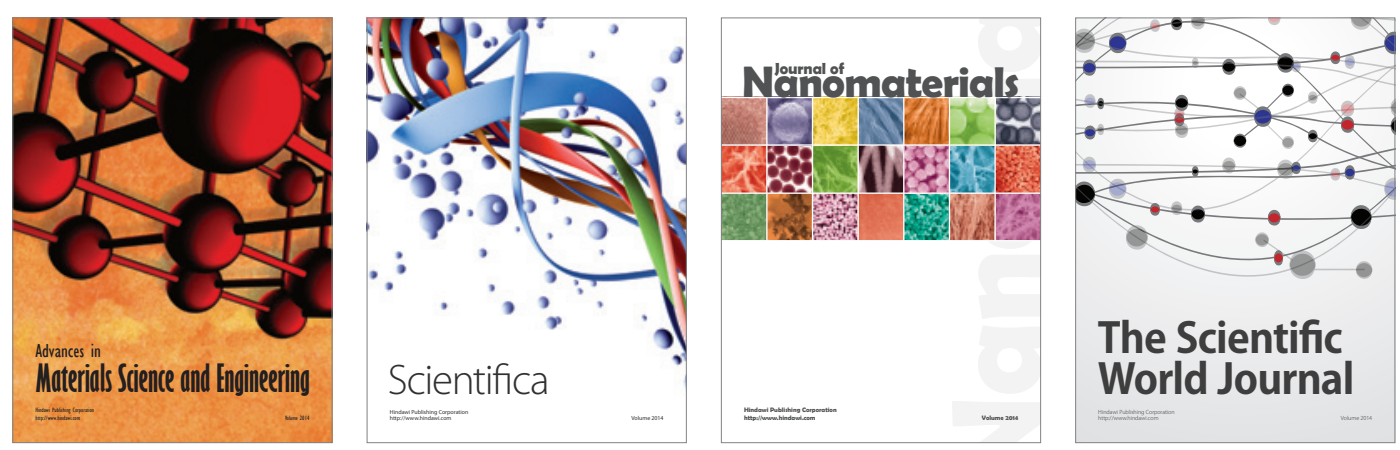

\section{The Scientific World Journal}
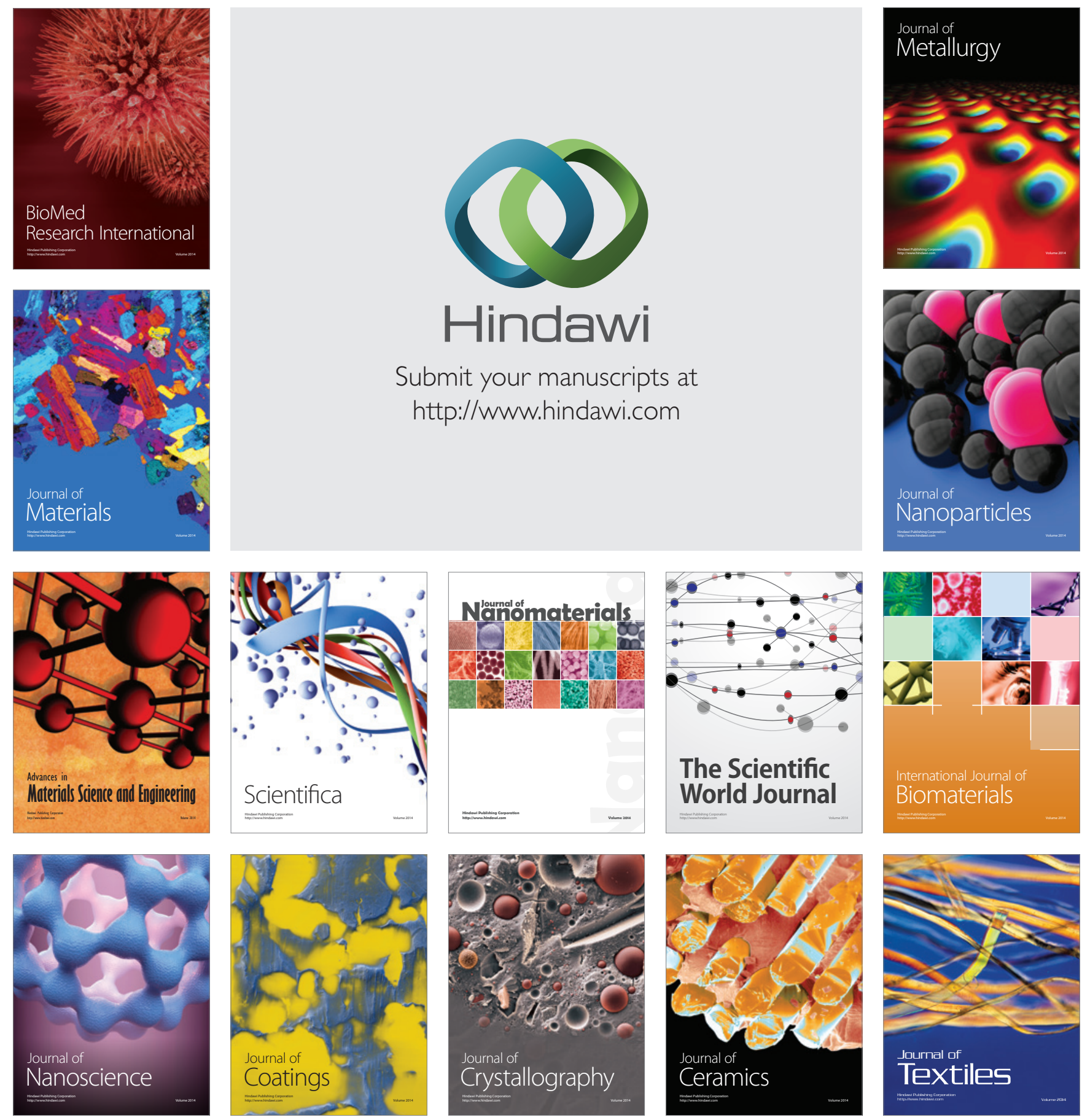